\title{
Asperity-based earthquake likelihood models for Italy
}

\author{
Laura Gulia ${ }^{1, \star}$, Stefan Wiemer ${ }^{2}$, Danijel Schorlemmer ${ }^{3}$ \\ ${ }^{1}$ Istituto Nazionale di Geofisica e Vulcanologia, sezione di Bologna, Italy \\ ${ }^{2}$ ETH Zurich, Swiss Seismological Service, Zurich, Switzerland \\ ${ }^{3}$ Southern California Earthquake Center, University of Southern California, Los Angeles, USA
}

\author{
Article history \\ Received March 25, 2010; accepted August 24, 2010. \\ Subject classification: \\ Earthquake forecasting, b-values, Statistical seismology, Seismotectonics, Seismic hazard.
}

\section{ABSTRACT}

The Asperity Likelihood Model (ALM) hypothesizes that small-scale spatial variations in the b-value of the Gutenberg-Richter relationship have a central role in forecasting future seismicity. The physical basis of the ALM is the concept that the local b-value is inversely dependent on the applied shear stress. Thus low b-values $(b<0.7)$ characterize locked patches of faults, or asperities, from which future mainshocks are more likely to be generated, whereas high b-values $(b>1.1)$, which can be found, for example, in creeping sections of faults, suggest a lower probability of large events. To turn this hypothesis into a forecast model for Italy, we first determined the regional $b$ value $(b=0.93 \pm 0.01)$ and compared it with the locally determined $b$-values at each node of the forecast grid, based on sampling radii ranging from $6 \mathrm{~km}$ to $20 \mathrm{~km}$. We used the local b-values if their Akaike Information Criterion scores were lower than those of the regional b-values. We then explored two modifications to this model: in the ALM.IT, we declustered the input catalog for $M \geq 2$ and smoothed the node-wise rates of the declustered catalog with a Gaussian filter. Completeness values for each node were determined using the probability-based magnitude of completeness method. In the second model, the hybrid ALM (HALM), as a "hybrid" between a grid-based and a zoning model, the Italian territory was divided into eight distinct regions that depended on the main tectonic regimes, and the local b-value variability was thus mapped using the regional b-values for each tectonic zone.

\section{Introduction}

Asperities are the locked parts of a fault system that accumulate stress and release most of the energy as large ruptures. Mapping asperities would thus be equivalent to mapping the locations of the most likely nucleation points of future mainshocks. However, no techniques are currently available to map the state of stress along a fault. A number of laboratory and seismicity studies [e.g., Scholz 1968, Wiemer and Wyss 1997, Amitrano 2003, Schorlemmer and Wiemer 2005, Schorlemmer et al. 2005] have suggested that the relative earthquake-size distribution, or $b$-value $(\log N=$ $a-b M$, where $N$ is the cumulative number of events with magnitude $M$ or larger, and $a$ and $b$ are constants that describe the productivity and relative size distribution, respectively), is inversely proportional to the applied shear stress.

Based on this concept, Schorlemmer and Wiemer [2005] suggested that the $b$-value can be used as a "stressmeter» to identify asperities. According to their hypothesis, low $b$-values $(b<0.7)$ characterize the locked patches of faults, or asperities, whereas high $b$-values $(b>1.1)$ mark low stressed or creeping sections [see also Amelung and King 1997]. This hypothesis was first developed by Wiemer and Wyss [1997] for two segments of the San Andreas fault, USA, where the locations of asperities were known: the Parkfield and the northern Morgan Hill rupture zones. In both cases, low $b$-value patches correlated with known asperities, supporting the concept that the observed spatial variability in $b$-values is indeed largely due to the influence of the stress. Detailed mapping of the earthquake-size distribution along the seismically wellmonitored region of the San Jacinto-Elsinore fault system in southern California, USA, confirmed the use of low $b$-values as indicators of high applied shear stress [Wyss et al. 2000]. The area investigated in most detail has been the Parkfield segment of the San Andreas fault. Schorlemmer et al. [2004a, $2004 \mathrm{~b}$ ] performed a detailed survey of local $b$-values along a $100-\mathrm{km}$-long segment of the fault. Mapping with radii of $5 \mathrm{~km}$, they found that the $b$-value in the asperity was about 0.5 , whereas it reached values of up to 1.35 in the creeping section. The Parkfield earthquake on September 28, 2004, $(M=6.0)$ occurred in an area of low $b$-values, where Schorlemmer et al. [2004a, 2004b] and Wiemer and Wyss [1997] had pinpointed the highest probability for an M6 event. Schorlemmer and Wiemer [2005] showed that both the slip distribution and the aftershock distribution of the 2004 event correlated closely with the pre-event $b$-values, which led them to propose their stressmeter hypothesis.

Starting from these specific case studies, Wiemer and Schorlemmer [2007] created a regional forecast model, the Asperity Likelihood Model (ALM) [Wiemer and Schorlemmer 2007] to systematically test the stressmeter hypothesis in a fully 


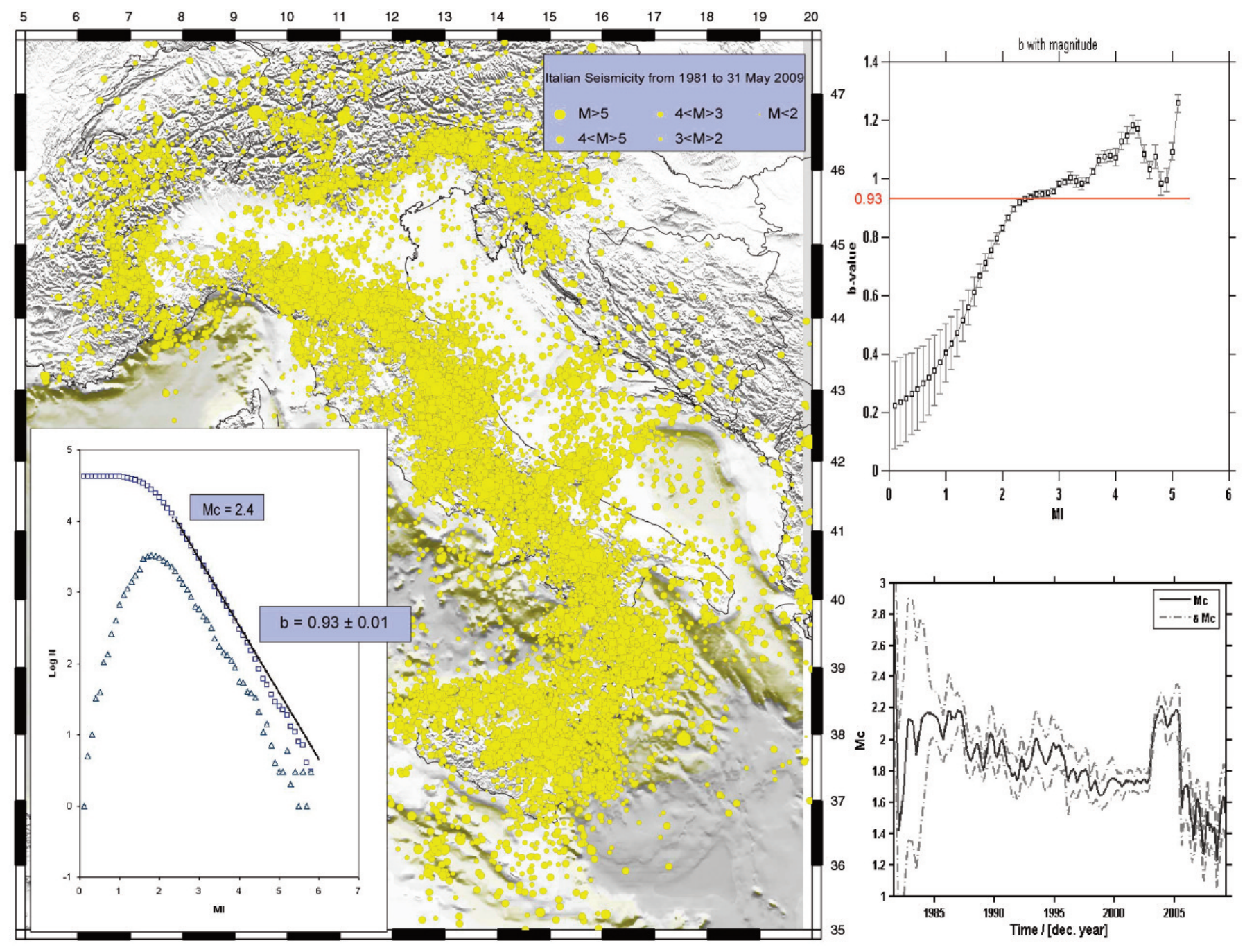

Figure 1. Left: Italian seismicity from 1981 to May 31, 2009, with the frequency-magnitude distribution (squares, cumulative; triangles, not-cumulative) obtained for the overall merged catalog adopted for the ALM and HALM. Right: The $b$-value as a function of the magnitude cut-off (top; red line, adopted $b$-value), and the magnitude of completeness as a function of time (bottom; sample size, 500 events).

prospective experiment. The model was first developed for the Regional Earthquake Likelihood Model working group (RELM; www.relm.org) [Field 2007] and it is currently being tested for California by the Collaboratory for the Study of Earthquake Predictability (CSEP; www.cseptesting.org) [Schorlemmer et al 2010a].

Schorlemmer et al. [2010a] investigated the performance of the ALM halfway through the forecast period of 5 years. The results stated that the forecast rates of the ALM were consistent with the observations, and that the ALM was only rejected in the R-Test by one model [Helmstetter et al. 2007]. These preliminary results suggested that the ALM can indeed perform reasonably well, and encouraged us to apply it to other regions. By comparing the performances of the same models, or classes of models, in different testing regions and under different tectonic settings, it will be possible to formulate conclusions more rapidly of the forecasting power of models (i.e., trading space for time).

The Italian testing region was the first implemented region in the CSEP European Testing Center. The testing region and testing set-up are described in the Preface to this special issue, and in Schorlemmer et al. [2010b]. While in Italy the overall rate of seismicity is lower than in California, the monitoring of micro-seismicity is well established, and good instrumental earthquake catalogs that span the past 30 years are available. It was thus feasible and desirable to apply the ALM to Italy. In contrast to California, seismicity in Italy is less concentrated on known faults; asperity mapping in the context of the ALM might thus lead to less-focused results.

Here, we have calibrated the ALM for implementation in the Italian testing region. Furthermore, the complex geology of the Italian territory, including the contemporary presence of extensional, compressional, and strike-slip regimes, offered an opportunity to prospectively test the influence of tectonic regimes on the earthquake-size distribution. We therefore developed a modified ALM approach, which introduced $b$-values for different tectonic areas. This model is based on the results of Gulia and Wiemer [2010], who explored the hypothesis that $b$-values in Italy depend systematically on the style of faulting of the seismotectonic zones. We could not adopt the most recent Italian seismotectonic zonations [e.g., Cinti et al. 2004, Meletti et al. 2008], because the scale of their 
zones is too small to allow for robust determination of specific faulting $b$-values and faulting styles. Based on a seismotectonic zonation model that consisted of eight distinct tectonic zones, Gulia and Wiemer [2010] showed that $b$ (thrust) $<b$ (strike-slip) $<b$ (normal), which confirmed the results of Schorlemmer et al. [2005]. Here we have exploited this result for a modified ALM, which we call the hybrid ALM (HALM).

\section{The data}

\section{ALM and HALM:}

For calibration of our forecasts against past seismicity, we created a reference dataset that followed the suggestions of Lolli and Gasperini [2006]. We merged the catalog of Italian seismicity (Catalogo della Sismicità Italiana, C.S.I. 1.1) [Castello et al. 2006] that covers the period of 1981-2002, with the Italian seismic bulletin (Bollettino Sismico Italiano, edited by the Istituto Nazionale di Geofisica e Vulcanologia and available at http:/ / bollettinosismico.rm.ingv.it/) for the period January, 2003, to February, 2009. Finally, we added the earthquakes from March, 2009, to May, 2009, from the Italian Seismic Instrumental and parametric Data-basE (ISIDe; available at http://iside.rm.ingv.it/iside/standard/index.jsp). Sources of error using different catalogs are generally seen in the different magnitudes and location uncertainties. All of the magnitudes were made homogeneous, as $M_{\mathrm{L}}$ (Lolli, personal communication), to issue a forecast that was consistent with the authoritative testing dataset [Schorlemmer et al. 2010b]. For $b$-value computations, we also used a catalog that has been declustered using the approach proposed by Reasenberg [1985] and applying the standard parameters derived for California. The objective of declustering in our context was to remove the biasing influence of individual aftershock sequences on $b$-values, because aftershock sequences tend to have higher $b$-values than the background seismicity [Wiemer and Katsumata 1999, Wiemer et al. 2002]. Finally, the presence of quarry and mine explosions was investigated, as these artificial events not only bias the rates, but can also promote substantial bias towards high $b$-values in some locations [Wiemer and Baer 2000]. Following the procedure outlines of Wiemer and Baer [2000] and Gulia [2010], we removed 6,719 probably quarry and mine blasts from the data. We considered only events with a maximum depth of 35 $\mathrm{km}$ : the final catalog contained 43,713 events from January, 1981, to May 31, 2009. For the final catalog, we estimated an overall $b$-value for Italy of $0.93 \pm 0.01$ (Figure 1), with a magnitude of completeness of 2.4 .

\section{ALM.IT:}

For ALM.IT, we took a somewhat different approach, and used two separate catalogs as input for the computation of the forecast rates of events. We computed the local $b$-values on the basis of only the Italian seismic bulletin for the period April
16, 2005, to April 1, 2009, and derived the forecast rates from it. These rates were then calibrated to the long-term rate average of events in the CPTI08 catalog, such that the forecast matched with the long-term occurrence rate of earthquakes of $M \geq 4.95$. The Italian seismic bulletin was previously cut at $<30-\mathrm{km}$ depths and magnitudes $M \geq 2$, then it was declustered using the method of Gardner and Knopoff [1974]. We chose to use this declustering method to avoid the completeness problems associated with the method of Reasenberg [1985], which assumed a homogeneous completeness. We used spatially varying completeness values, which were computed by Schorlemmer et al. [2010a] according to the probabilitybased method of Schorlemmer and Woessner [2008]; these values were also used to define the testing region by Schorlemmer et al. [2010b]. For each node of the forecast grid, we used the respective completeness value and cut the nodewise sub-catalog accordingly.

To check our forecast rates against independent data, we compared them with the CPTI08 catalog (available at http://www.cseptesting.org/regions/italy), which contains 916 events from 1950 to 2006 [Schorlemmer et al. 2010b].

\section{The models}

We computed three 5 -year forecasts over the period of December 1, 2009, to December 1, 2014, and three 10-year forecasts over the period of December 1, 2009, to December 1,2019 , for Italy, each in the magnitude range of 5.0 to 9.0. Two of the forecasts were based on the ALM [Wiemer and Schorlemmer 2007], but with different choices for the magnitude of completeness and the a-value smoothing, and one was based on the HALM, a modified approach that took into account the tectonic settings of the region, according to Gulia and Wiemer [2010]:

\section{The ALM:}

As applied here, the ALM is to a great extent identical to that defined by Wiemer and Schorlemmer [2007] for California. The definition of the local magnitude of completeness, $M_{c}$, for the catalog was the first step. As the $M_{c}$ in Italy significantly varies spatially from north to south, a general cut applied to the catalog at the highest value encountered would greatly reduce the amount of data available at each node. The ALM tries to use as much as possible of the available microseismicity to provide maximum spatial resolution. Therefore, we computed a $M_{c}$ map based on the entire-magnitude range (EMR) method [Woessner and Wiemer 2005]. We used the un-declustered catalog, and estimate the $M_{c}$ on a $0.1^{\circ} \times 0.1^{\circ}$ grid based on the nearest 200 events to every node. The computed $M_{c}$ values were then smoothed using a Gaussian kernel with a width of $5 \mathrm{~km}$. The resulting $M_{c}$ map is shown in Figure 2A. The onshore $M_{c}$ values ranged from about 1.6 in central Italy to about 2.7 in parts of Sicily. The offshore $M_{c}$ values were considerably 

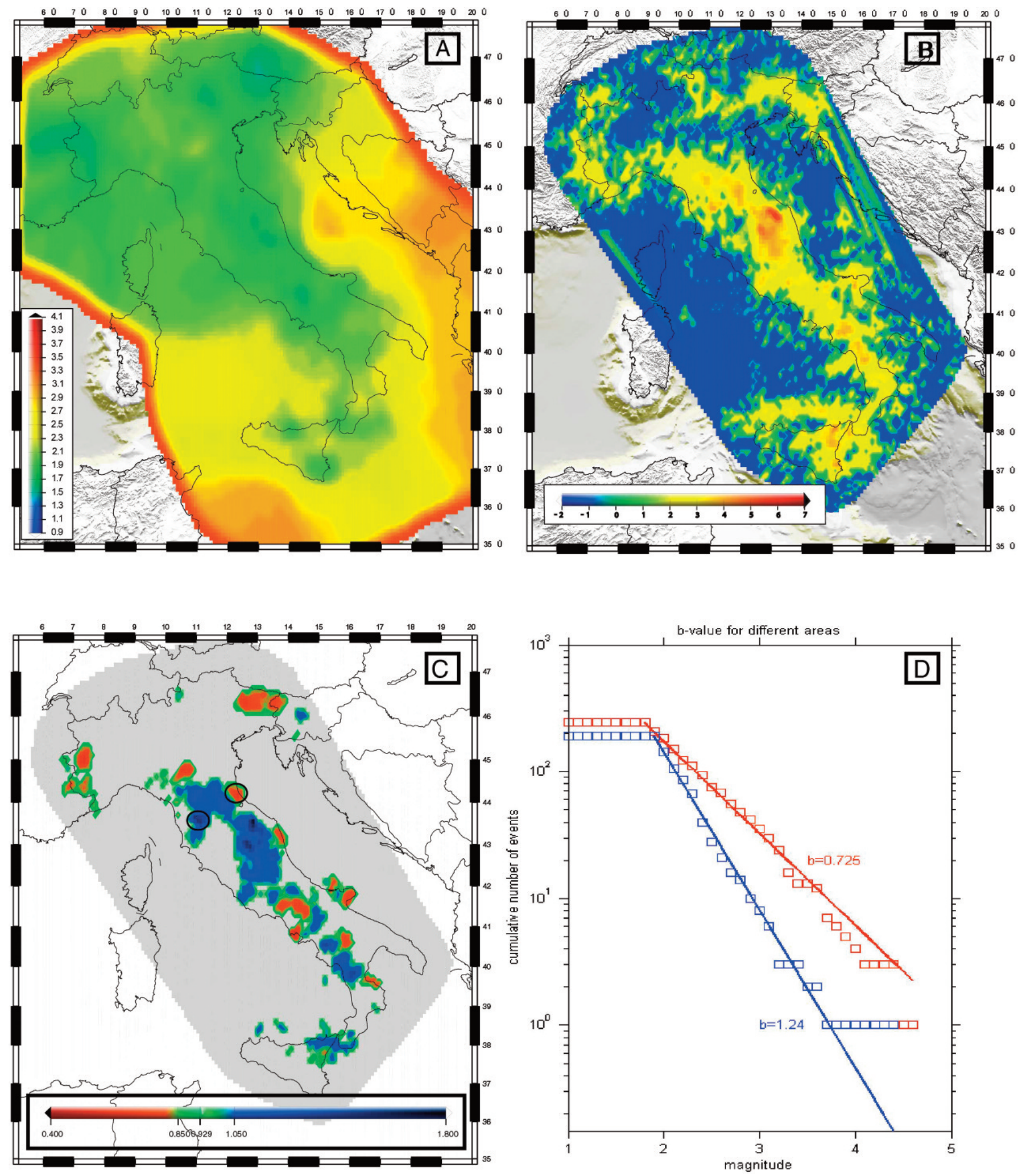

Figure 2. A) Magnitude of completeness map. B) The $a$-value map. C) The $b$-value map. Black circles, locations of the two areas. D) The frequencymagnitude distributions obtained from one area with a high $b$-value (blue line) and one area with a low $b$-value (red line).

higher, as expected.

The $b$-value at each node was then estimated by the maximum-likelihood method [Aki 1965, Bender 1983] at every node of the CSEP testing grid [Schorlemmer et al. 2010b], using the declustered catalog. At each node, we cut the catalog according to the local $M_{c}$ values and then computed the $b$-values based on the samples with radii from
$5 \mathrm{~km}$ to a maximum of $20 \mathrm{~km}$, using an iterative process. The $b$-values obtained (local, one degree of freedom) at the $5 \mathrm{~km}$ radius were compared to the regional $b$-values (global, zero degrees of freedom) using the corrected Akaike Information Criterion $\left(\mathrm{AIC}_{\mathrm{c}}\right.$ ) [Kenneth et al. 2002], as in Equation (1):

$$
\mathrm{AIC}=-2 \max (\ln L)+2(P)+\frac{2 P(P+1)}{N-P-1}
$$



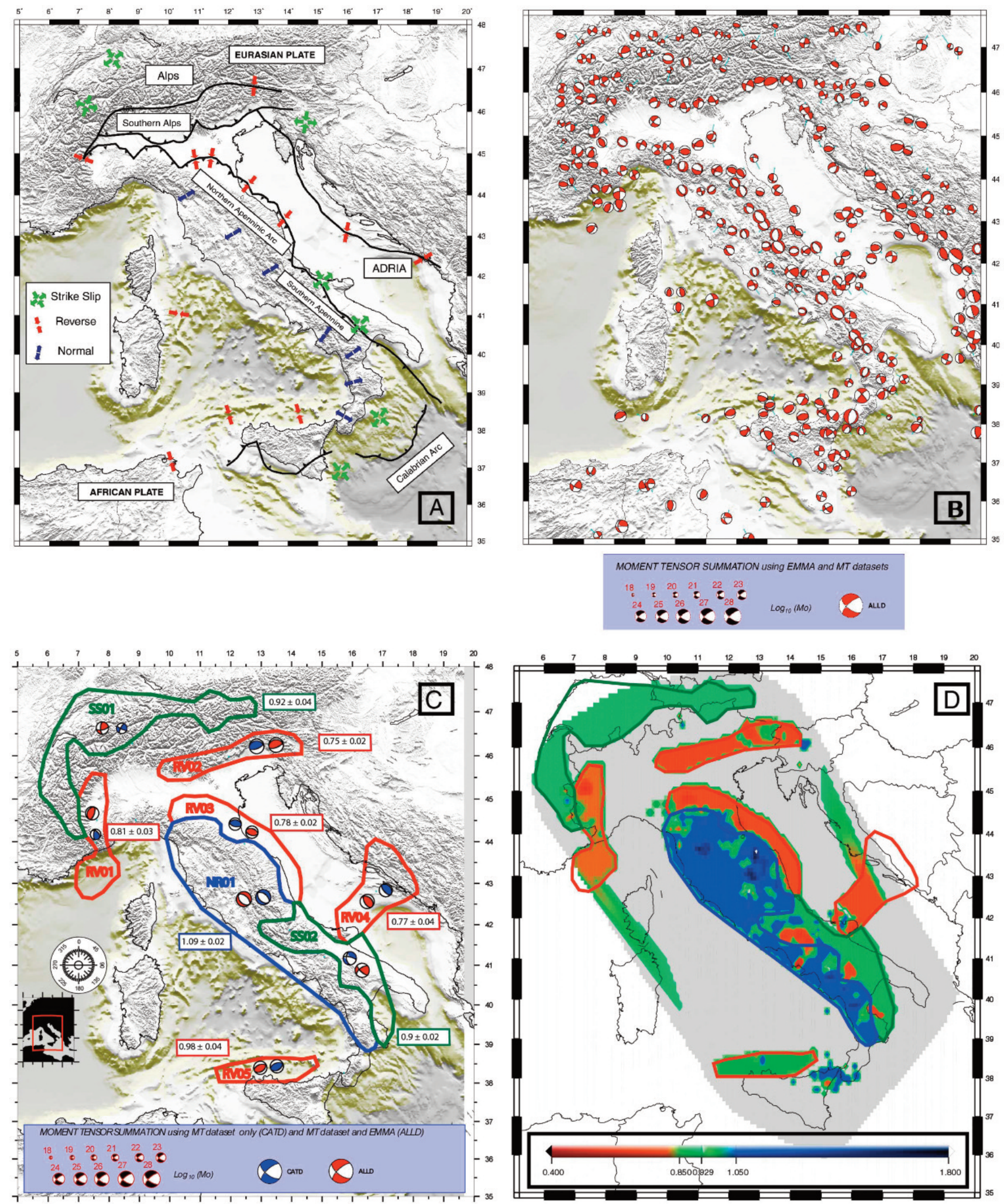

Figure 3. A) Structural model of Italy with the directions of the inferred regional stress regimes (from Montone et al. 2004). Red arrows, compressional; blue arrows, extensional; green arrows, strike-slip. B) Sum of the moment tensors on a grid with a mesh of one degree for earthquakes with depths $\leq 35 \mathrm{~km}$ (elaboration by Gianfranco Vannucci), using the moment tensor and the EMMA [Vannucci and Gasperini 2003, Vannucci and Gasperini 2004] dataset. C) Tectonic zonation with relative $b$-values and moment tensor summation (from Gulia and Wiemer 2010). D) The HALM-based $b$-value map and seismotectonic zonation.

where $\ln L(a, b)$ is the likelihood function, $P$ is the number of free parameters, and $N$ is the sample size. The model with the lowest $\mathrm{AIC}_{\mathrm{c}}$ was the preferred model. If the $\mathrm{AIC}_{\mathrm{c}}$ of the local model was lower than the global one, we used the local $b$-value. If, on the other hand, the regional $\mathrm{AIC}_{c}$ was lower, we increased the sampling radius in 1-km steps until the local $b$-value was lower than the regional $b$-value. If the regional $b$-value for a sampling radius of $20 \mathrm{~km}$ was still greater, we stopped the procedure and used the regional $b$-value. This procedure was repeated at each node of the grid, which 

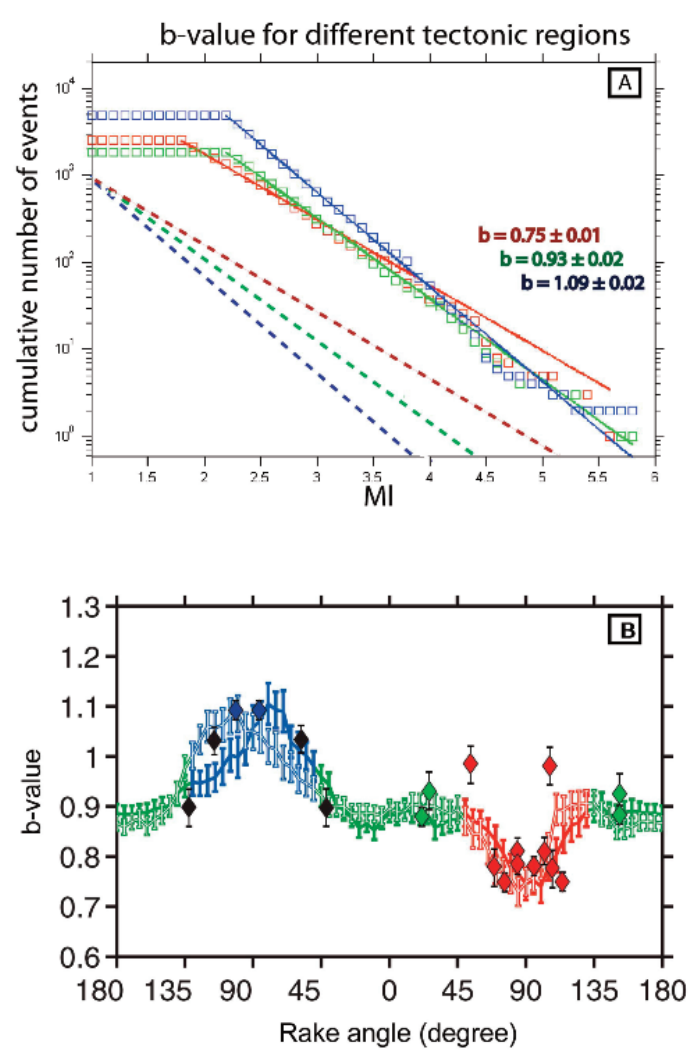

Figure 4. A) The frequency-magnitude distributions obtained from three tectonic regimes: normal (blue line, NR01); reverse (red line, sum of RV01, RV02, RV03, RV04) and strike-slip (green line, sum of SS01, SS02) and their normalized distributions (dotted lines), using a common $a$-value (103). B) The $b$-values for each zone (blue, red, green diamonds), using the two rake angles of the summation of the moment tensor on the modified plot by Schorlemmer et al. [2005] (both graphs from Gulia and Wiemer 2010).

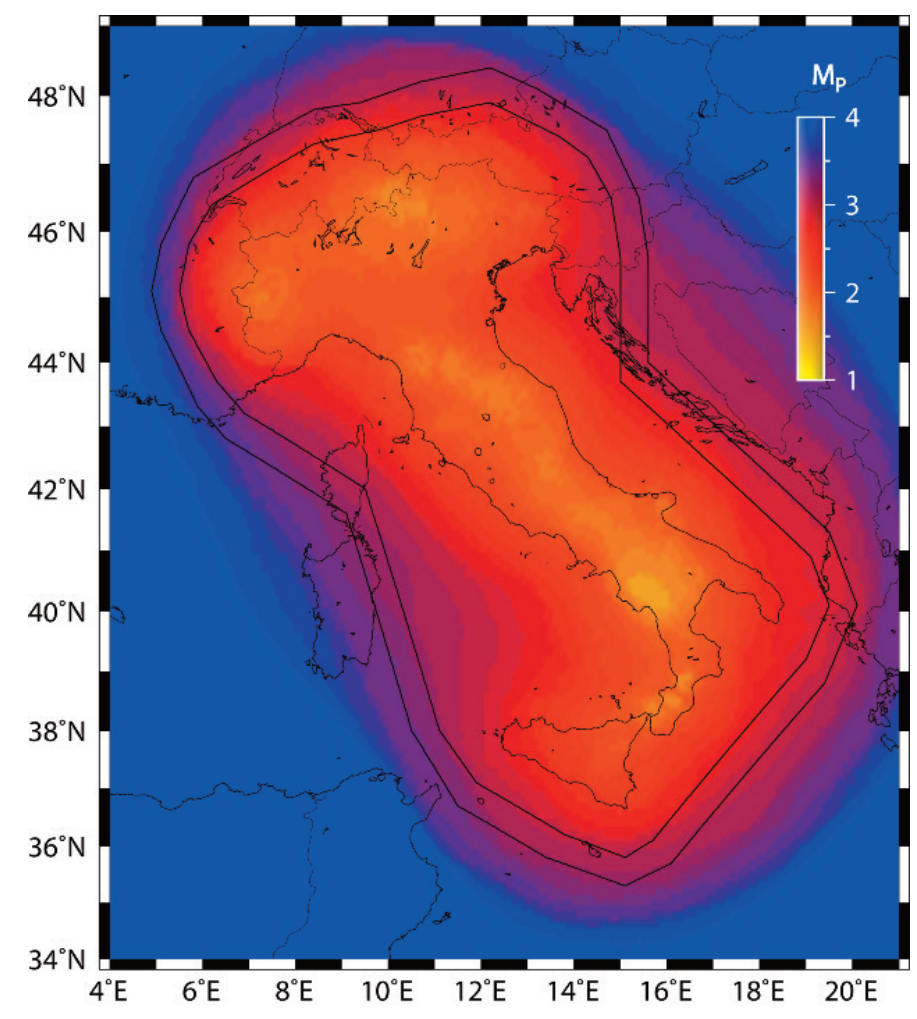

Figure 5. Probability-based magnitude of completeness map. The map was computed for January 1, 2008, for a probability level of 0.999 . The black polygons indicate the testing (inner) and collection (outer) area. resulted in a map of $b$-values (Figure $2 \mathrm{C}$ ). We compared the $b$-values at two representative nodes (Figure 2D), and found that the differences ( 0.72 versus 1.24 ) were highly statistically significant, as well as visually convincing. Much of the map, however, was shaded in gray, indicating that the regional $b$-values provided an adequate fit to the data.

The $a$-value at $M=0$ at each node was then determined, based on the observed number of events within each $0.1^{\circ} \times 0.1^{\circ}$ cell of the grid and the $b$-value selected at this node. Consequently, the $a$-value map (Figure 2B) was not as smooth as the $b$-value map. If a node had no events, we assumed a «water level» $a$-value of -2 at $M=0$ (Figure $2 \mathrm{C}$ ).

\section{The HALM:}

The map of the $b$-values computed based on the ALM approach (Figure $2 \mathrm{C}$ ) outlines the strong spatial variability of the $b$-value, which ranged from about $b=0.5$ to $b=1.6$. The variations were systematically correlated with the seismotectonics of the regions: the areas with the lowest $b$ values corresponded to compressional regimes, while those with the highest $b$-values indicated predominately normal faulting. A systematic study of the dependence of the $b$-value on the faulting regime in Italy was performed by Gulia and Wiemer [2010]. They presented a new regional seismotectonic zonation model for Italy, which was derived by analyzing a wide range of geophysical, geological and geodetic datasets [see Gulia and Wiemer 2010, for details]. In Figure 3A, we show the major tectonic provinces of the region. The datasets of the focal mechanisms derived from both the first motion and the full waveform analyses are of critical importance for the derivation of the zonation model, and also for determination of the predominant style of faulting (EMMA; Figure 3B) [Vannucci and Gasperini 2003, Vannucci and Gasperini 2004]. Gulia and Wiemer [2010] computed a composite focal mechanism for each zone (Figure 3C) [Kostrov 1974], which determined the style of faulting. The final zonation model consisted of one normal (NR01), five reverse (RV01-05), and two strike-slip (SS01-02) zones (Figure 3B). The $b$-values computed using the same dataset of earthquakes analyzed in this study showed that $b$ (thrust) $<b$ (strike-slip) $<b$ (normal). The composite frequency-magnitude distributions are shown in Figure 4A. The observed faulting-style dependence, and even the absolute $b$-values, were fully consistent with the findings of Schorlemmer et al. [2005] for California, Japan, and the global Harvard catalog (Figure 4B), which suggested that the stressmeter hypothesis can also be applied to Italy.

Gulia and Wiemer [2010] finally suggested that the differences observed in the $b$-values between the tectonic regimes should be used as the input in the Probabilistic Seismic Hazard Assessment (PSHA) models, and this was the starting point for the HALM. In contrast to the ALM, we did not use a single overall $b$-value for all of Italy; instead, we set 
the initial default $b$-value for each zone. This was the only modification for HALM with respect to ALM. The model is called «hybrid» as the approach is a hybrid between a fully grid-based and a more traditional seismotectonic zonation hazard assessment. The local $b$-values and $a$-values were then computed following the same procedures as detailed for the ALM. If the HALM was to perform significantly better than the ALM, we would interpret this as evidence that a regionalization of the $b$-values based on the tectonic faulting style is meaningful. The final $b$-value map from the HALM approach (Figure 3D) did indeed vary significantly from that of the ALM (Figure 2C). In particular, the overall $b$-values adopted for most of the areas in the HALM ( 0.81 for RV01, 0.75 for RV02, 0.78 for RV03, 0.77 for RV04, 0.92 for SS01 and 0.09 for SS02) were lower than the overall $b$-value adopted for the ALM (0.929). This led to more grid points with a lower $b$-value in the HALM.

\section{The ALM.IT:}

The ALM.IT created a forecast in a similar way to the ALM. The differences were mainly in the smoothing of the observed earthquake rates. The ALM.IT used both the Italian seismic bulletin and the CPTI08 catalog. The first of these catalogs was prepared as described in the data section. We calculated the regional $b$-values from this catalog for all magnitudes $M \geq 2.5$. Instead of estimating the $a$-values nodewise, we computed the earthquake rates for each grid node and smoothed them using a $0.2^{\circ}$ Gaussian kernel. If after smoothing, the nodes showed a zero rate of events, we set the $a$-value for this node to -9 . This value was much lower than that used in the ALM because the nodes without activity even after smoothing indicated non-active regions. In the ALM, we had to account for strong spatial heterogeneities in activity due to the binning of the nodes, and an intermediate value of $a=-2$ was more appropriate. We computed the nodewise $b$-values (using a maximum radius of $25 \mathrm{~km}$ ) and derived the forecast rate per magnitude in the same way as was done in the ALM, except for the completeness estimate. Here, we used per-node-probability-based completeness magnitudes, $M_{\mathrm{p}}$, as computed by Schorlemmer et al. [2010c] (Figure 5) using the probabilistic magnitude of completeness (PMC) method developed by Schorlemmer and Woessner [2008]. Due to the smoothing, we recalibrated the resulting forecast to the long-term average of $M \geq 4.95$ events in the CPTI08 catalog.

\section{Results and discussion}

Using nodewise $a$-values and $b$-values, we forecast the 5 year and 10-year rates of events of $5.0 \leq M \leq 9.0$ for the entire testing region. The forecast rates for each of the three models are shown in Figure 6. For the period 2009-2014, the ALM predicted a total of 8.09 events, the ALM.IT predicted a total of 8.68 events, and the HALM predicted a total of 8.47 events.

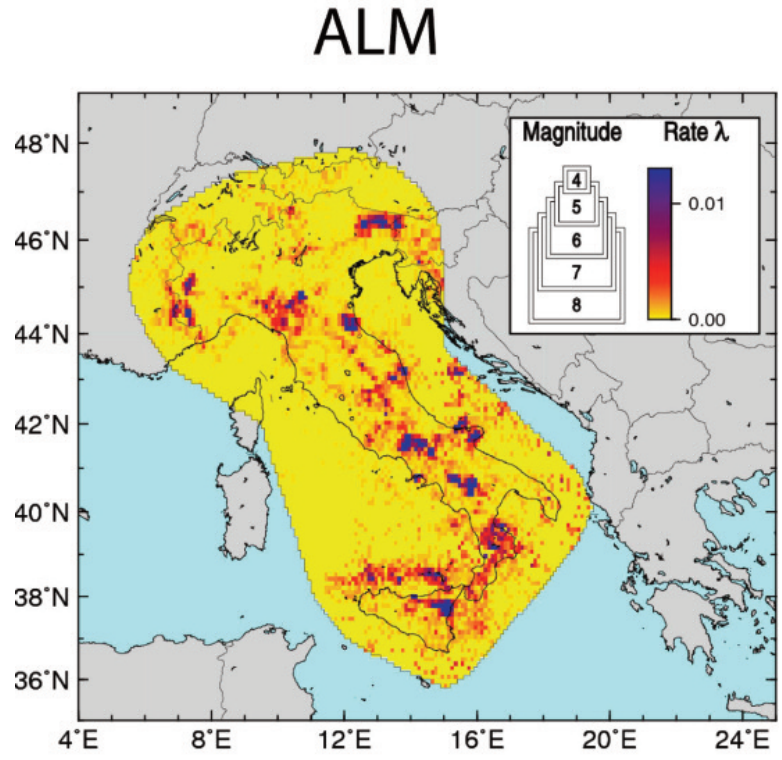

HALM

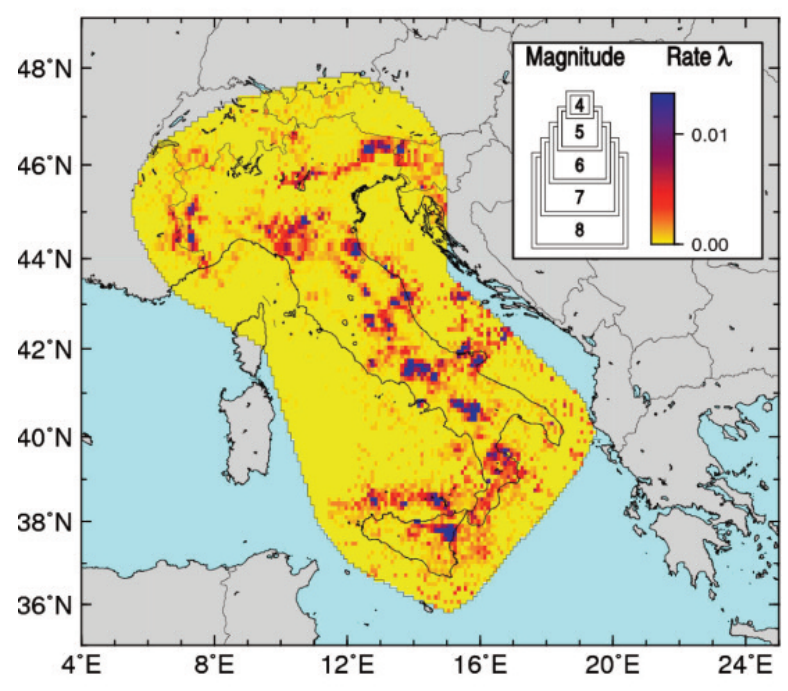

ALM.IT

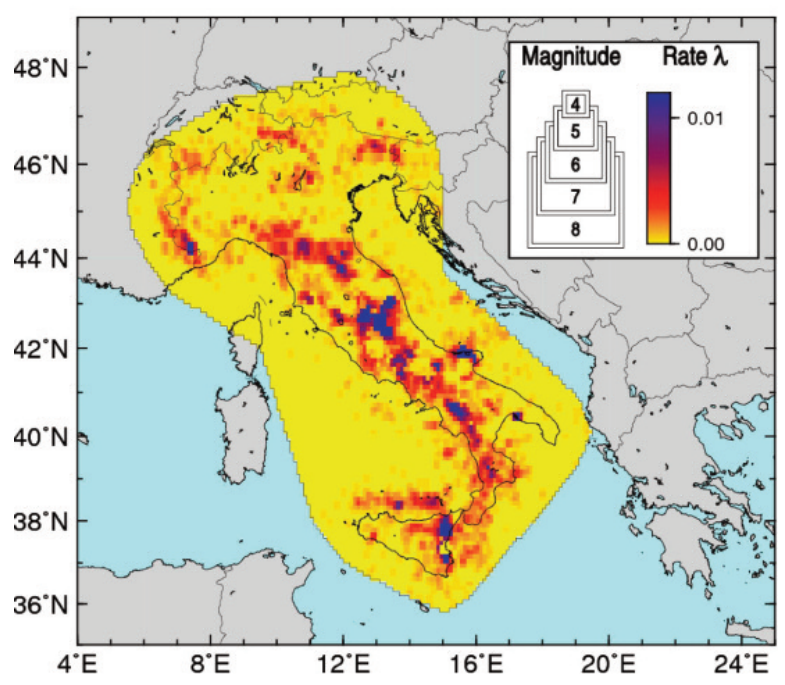

Figure 6. The 5-year forecast rates for the ALM (top), the HALM (middle) and the ALM.IT (bottom). 


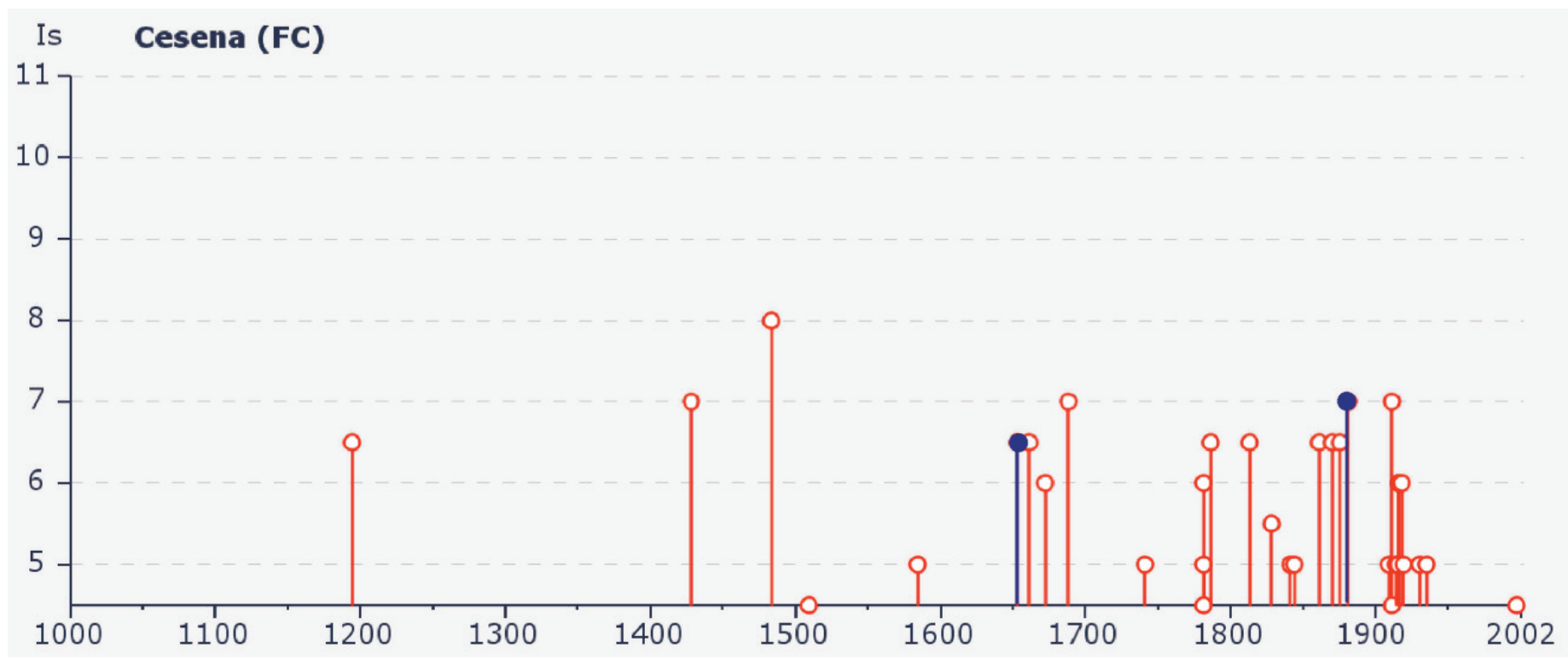

Figure 7. Seismic history of the city of Cesena, from the Italian macroseismic database (Database Macrosismico Italiano, DBM04; available online at http:/ / emidius.mi.ingv.it/DBMI04/) [Stucchi et al. 2007]. Blue lines, the two events that occurred in the city of Cesena.
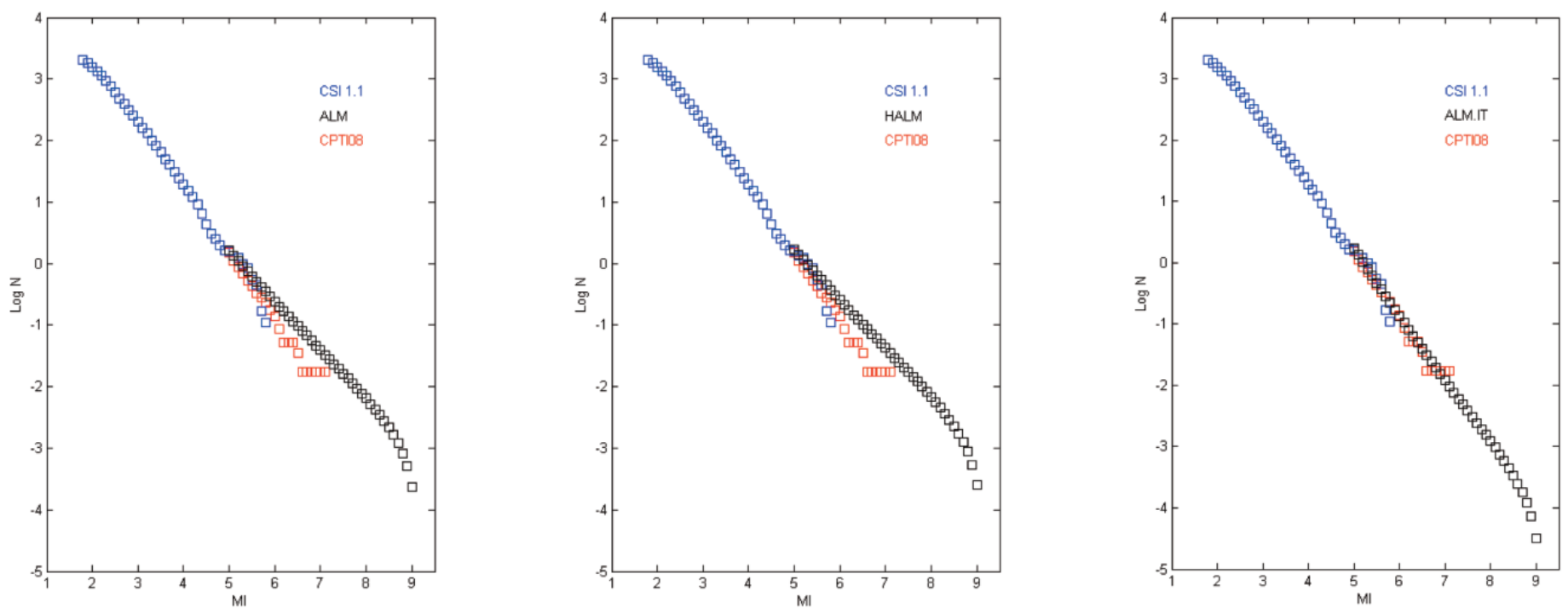

Figure 8. Annual frequency-magnitude distributions of the forecast rates for the three models (black squares, ALM, HALM, ALM.IT) against the observed rates: CSI 1.1 [Castello et al. 2006] from 1983 to 2002 (blue squares); the CPTI08 (http:/ / eu.cseptesting.org/; red circles).

As the model was not time-dependent, twice these rates were predicted for the period 2009-2019. The difference in the number of $M \geq 5$ events predicted between the ALM and the HALM were due to the greater number of grid points with lower $b$-values in the HALM. The highest rate for a $M \geq 5$ event for both models was located at $12.250^{\circ} \mathrm{E}$ and $44.150^{\circ}$ $\mathrm{N}$, close to the city of Cesena, while the ALM.IT gave the highest rate in the area of Messina, Sicily. The rate there was highest because of the low $b$-value, of $b=0.72$, as also shown in Figure 2D. We plotted the seismic history of events felt in Cesena (events with an epicentral intensity $I_{0} \geq$ IV) over the last millennium as Figure 7 (Database Macrosismico Italiano, DBM04; http:/ / emidius.mi.ingv.it/DBMI04/) [Stucchi et al., 2007]. From Figure 7, we can see that no intensity larger than IV has been seen over the past 50 years, and thus none is contained in the data we used to derive the models. Intensities of VII and more, however, have occurred several times over the past 500 years.

As a simple "sanity check", we compared the summed forecast annual rates for each model with the observed seismicity of the last century collected in the CPTI08 catalog (http:/ / www.cseptesting.org/regions/italy), cut for the year 1950 and at magnitude 5, and with the CSI 1.1 catalog [Castello et al. 2006], cut for the year 1983 and at magnitude 2.4. Figure 8 shows the plot of the annual frequencymagnitude distributions of the forecast rates for these two catalogs. The maximum observed magnitude $\left(M_{\mathrm{L}}\right)$ in CPTI08 was 7.1 and in CSI 1.1, 5.9, whilst our forecasts predicted events up to $M 9$, i.e. the upper magnitude threshold imposed for the CSEP experiment. While the overall shapes of the frequency-magnitude distributions of the forecast and the past events were quite similar, the ALM and HALM slightly 


\begin{tabular}{|c|c|c|c|c|c|}
\hline $\begin{array}{l}\text { Longitude } \\
\qquad\left({ }^{\circ} \mathrm{E}\right)\end{array}$ & $\begin{array}{l}\text { Latitude } \\
\qquad\left({ }^{\circ} \mathbf{N}\right)\end{array}$ & $\begin{array}{c}\text { Date } \\
\text { (dd.mm.yy) }\end{array}$ & $M_{\mathrm{L}}$ & $\begin{array}{l}\text { Depth } \\
(\mathbf{k m})\end{array}$ & $\begin{array}{c}\text { Time } \\
\text { (hh:mm:ss) }\end{array}$ \\
\hline 13.654 & 38.381 & 06.09 .02 & 5.90 & 27.01 & 01:21:29 \\
\hline 14.893 & 41.716 & 31.10 .02 & 5.65 & 25.15 & $10: 32: 59$ \\
\hline 14.843 & 41.741 & 01.11 .02 & 5.63 & 21.36 & 15:09:02 \\
\hline 15.339 & 43.134 & 29.03 .03 & 5.4 & $\mathrm{NaN}$ & $17: 42: 14$ \\
\hline 11.380 & 44.255 & 14.09 .03 & 5.10 & 8.3 & $21: 42: 53$ \\
\hline 13.620 & 46.310 & 12.07 .04 & 4.98 & 11.4 & $13: 04: 06$ \\
\hline 15.446 & 43.135 & 25.11 .04 & 5.12 & 10 & $06: 21: 18$ \\
\hline
\end{tabular}

Table 1. List of observed earthquakes in the target period (2002-2006) recorded in the CPTI08 catalog (http:/ / www.cseptesting.org/regions/italy).

over predicted the rates of larger events, while the ALM.IT fit the past observations well.

As a more sophisticated retrospective validation, the forecast rates for the mainshocks for each model were tested for consistency with the historical seismicity (CPTI08, http:/ / www.cseptesting.org/regions/italy) within the testing region, using two of the CSEP statistical tests [Schorlemmer et al. 2007, Werner and Sornette 2008, Schorlemmer et al. 2010a] to evaluate probabilistic earthquake forecasts: the L(ikelihood)-Test and the N(umber)-Test.

The N-Test determines whether the forecast number of mainshocks $(\lambda)$ is consistent with the observed number $(\omega)$ through the Poisson cumulative distribution function (Poi), as $\delta=$ Poi $(\omega \mid \lambda)$. If $\delta$ is very small $(<0.025)$ or very large $(>0.975)$, the model is rejected and the forecast is considered to be inconsistent with the observations.

The L-Test indicates whether the rates and spatial/ magnitude distributions of the forecast are consistent with observations. The test simulated a fixed number of synthetic catalogs (here with 10,000 simulations) that are consistent with the forecast, and calculated their log-likelihoods for each latitude-longitude-magnitude bin. The results were compared with the log-likelihoods of the reference catalog (i.e. the earthquakes in the observation period) for the same bins. If the statistic $\gamma$ (the proportion of simulated log-likelihoods less than the observed) was low $(<0.05)$, the model was rejected, and if $\gamma$ was very high, the model was not rejected, as it should have predicted a realistic distribution, although the forecast was too smoothed [Schorlemmer et al. 2010a].

We performed these tests for the 5 -year forecasts using the last five years (2002-2006) of the reference catalog (CPTI08, cut at the year 1950) as the observation period: the seven observed events with magnitudes $\geq 4.95$ are listed in Table 1, and the results are shown in Table 2 and Figure 9. The ALM, HALM and ALM.IT forecasts were particularly consistent with the N-Test, but they only barely passes the L-Test.

As a final step, we also computed the forecast hazard of the ALM class, and compared this with the forecast rates of the model submitted by Meletti to the Collaboratory for the Study of Earthquake Predictability (CSEP; www.cseptesting. org), because this model is a typical zonation-based PSHA approach [MPS Working Group 2004]. For this, we used a common attenuation model, but no logic tree. The hazard was computed using OpenSHA. Note that the absolute values of the hazard were of no consequence in our assessment; however, the hazard integration is another way to study the differences between models. As shown in Figure 10, the hazard forecast by the ALM and HALM were very similar, although distinctly different from the ALM.IT forecast, for both the absolute level and the spatial distribution of the hazard. This difference in our interpretations was largely caused by the different approaches in estimating the local completeness; with ALM.IT we used generally higher values, because the PMC method is more conservative than the EMR approach [Nanjo et al. 2010]. All three ALM-based approaches were very different indeed from the long-term hazard model; as a result of the underlying seismic zonation model, the long-term hazard model distributed the hazard much more evenly throughout the region.

\section{Conclusions}

The ability to compare the forecast of the same model, or at least a class of models, for different testing regions and different tectonic regimes is one of the key elements for making progress in the study of earthquake-forecast models. This is one of the major reasons why in addition to California and Japan, we also developed the ALM for Italy, despite the lower, more distributed and less fault-centric seismicity that might not be the ideal testing region for the underlying hypothesis of the ALM. When compared with the original 


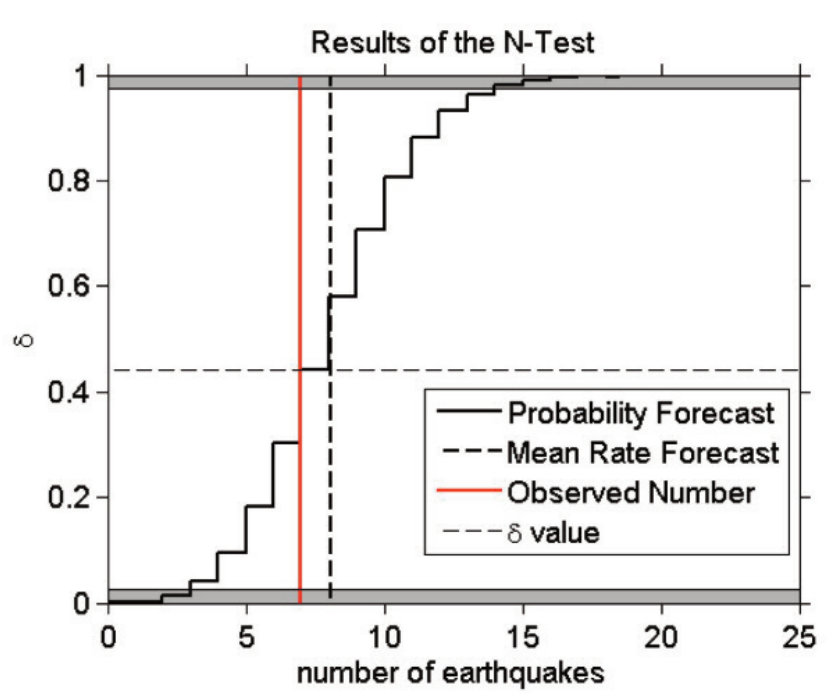

ALM
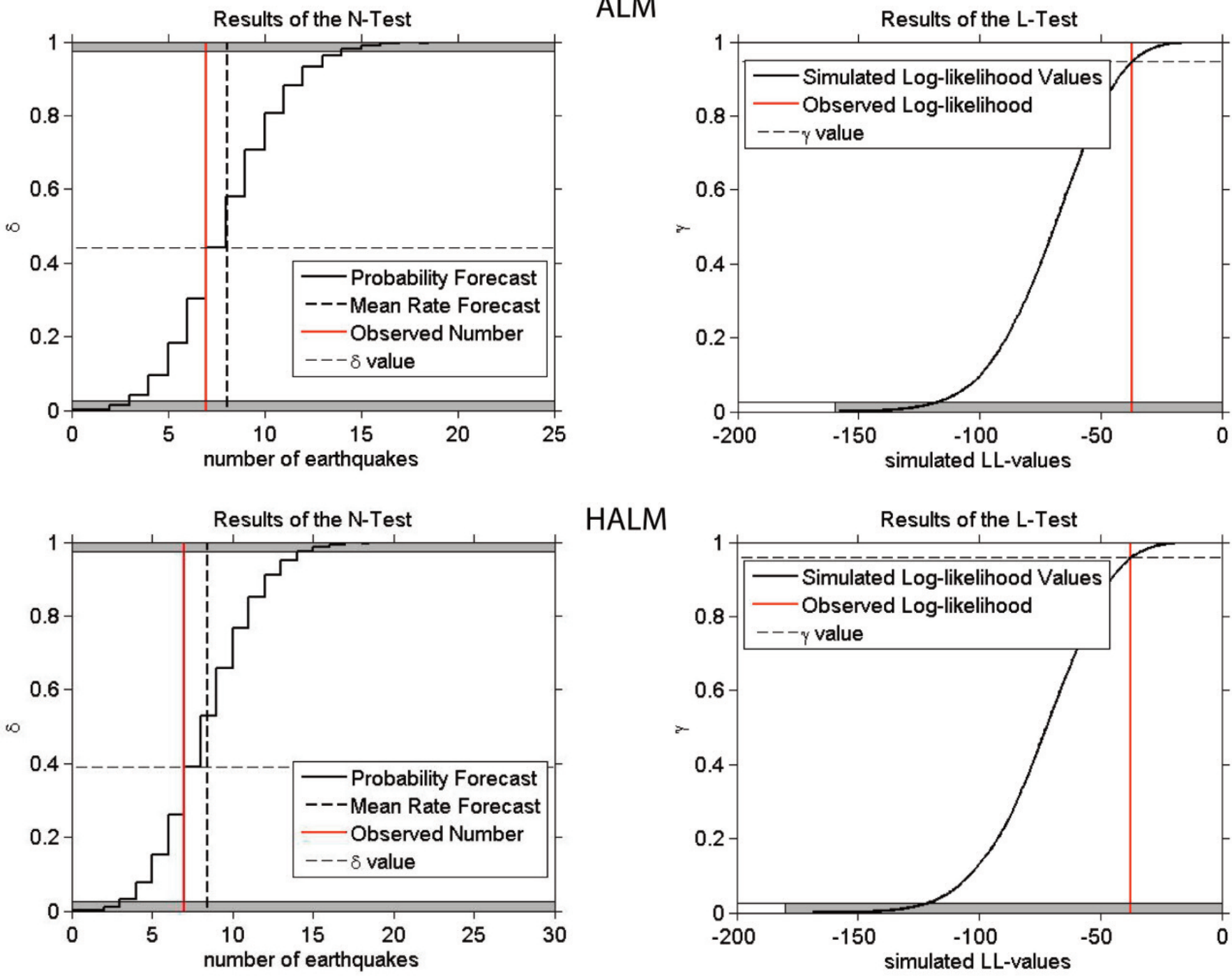

HALM
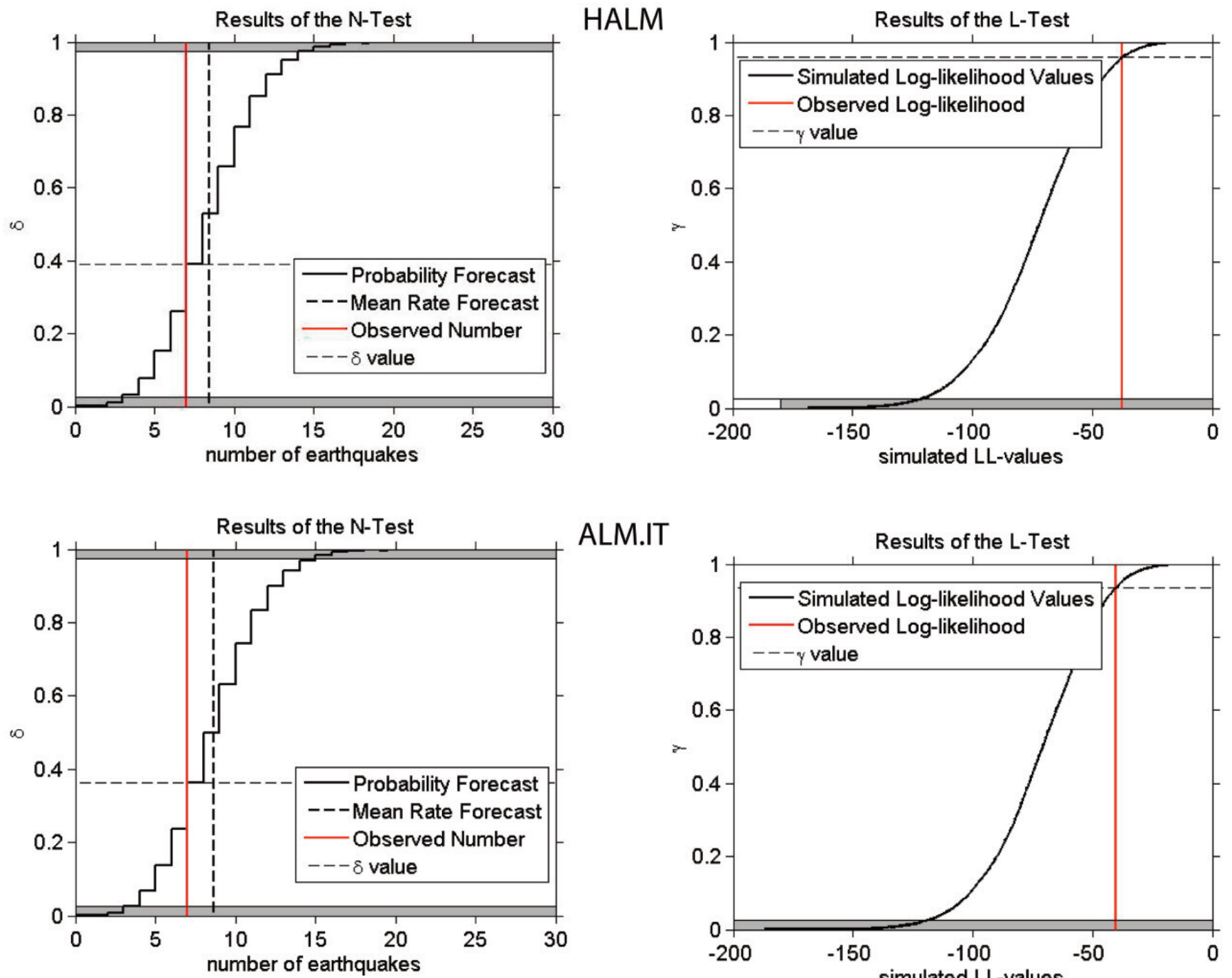

ALM.IT

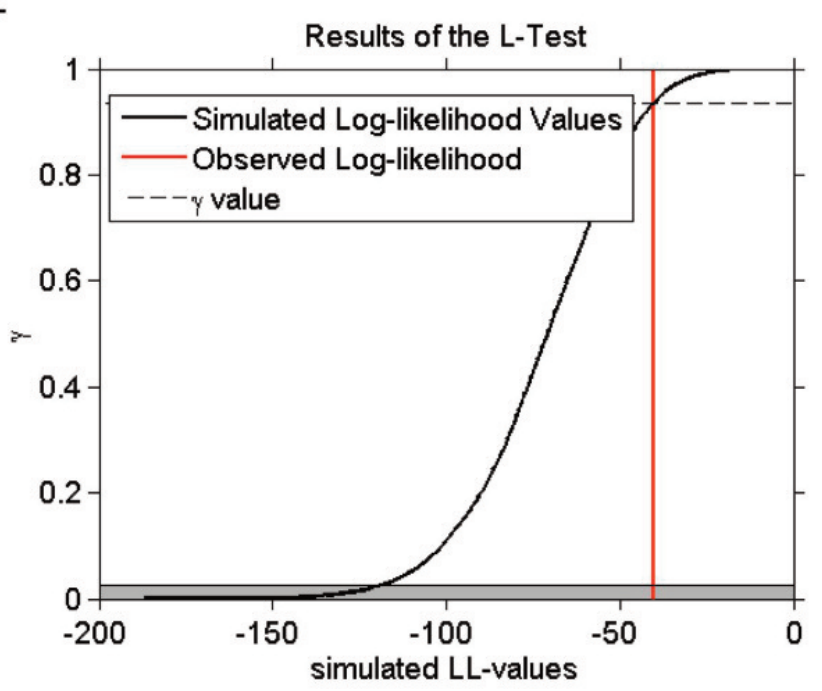

\begin{tabular}{lccc}
\hline Model & $\begin{array}{c}\text { Forecast events } \\
\boldsymbol{\lambda}\end{array}$ & $\begin{array}{c}\text { N-Test } \\
\boldsymbol{\delta}\end{array}$ & $\begin{array}{c}\text { L-Test } \\
\end{array}$ \\
\hline ALM & 8.09 & 0.44 & 0.95 \\
HALM & 8.46 & 0.39 & 0.96 \\
ALM.IT & 8.68 & 0.36 & 0.93 \\
\hline
\end{tabular}

Figure 9 (top). Retrospective N-Tests and L-Tests of the 5 -year forecasts (ALM, HALM) on past 5-year periods for the ALM (top), the HALM (middle) and ALM.IT (bottom). N-Test: vertical red line, number of observed events (7) in the 5-year target period (2002-2006); L-Test: the $\gamma$ values were calculated based on 10,000 simulations of log-likelihood values consistent with each model.

Table 2 (left). Total number of forecast events and results of retrospective $\mathrm{N}$-Test and L-Test for the three submitted models. 

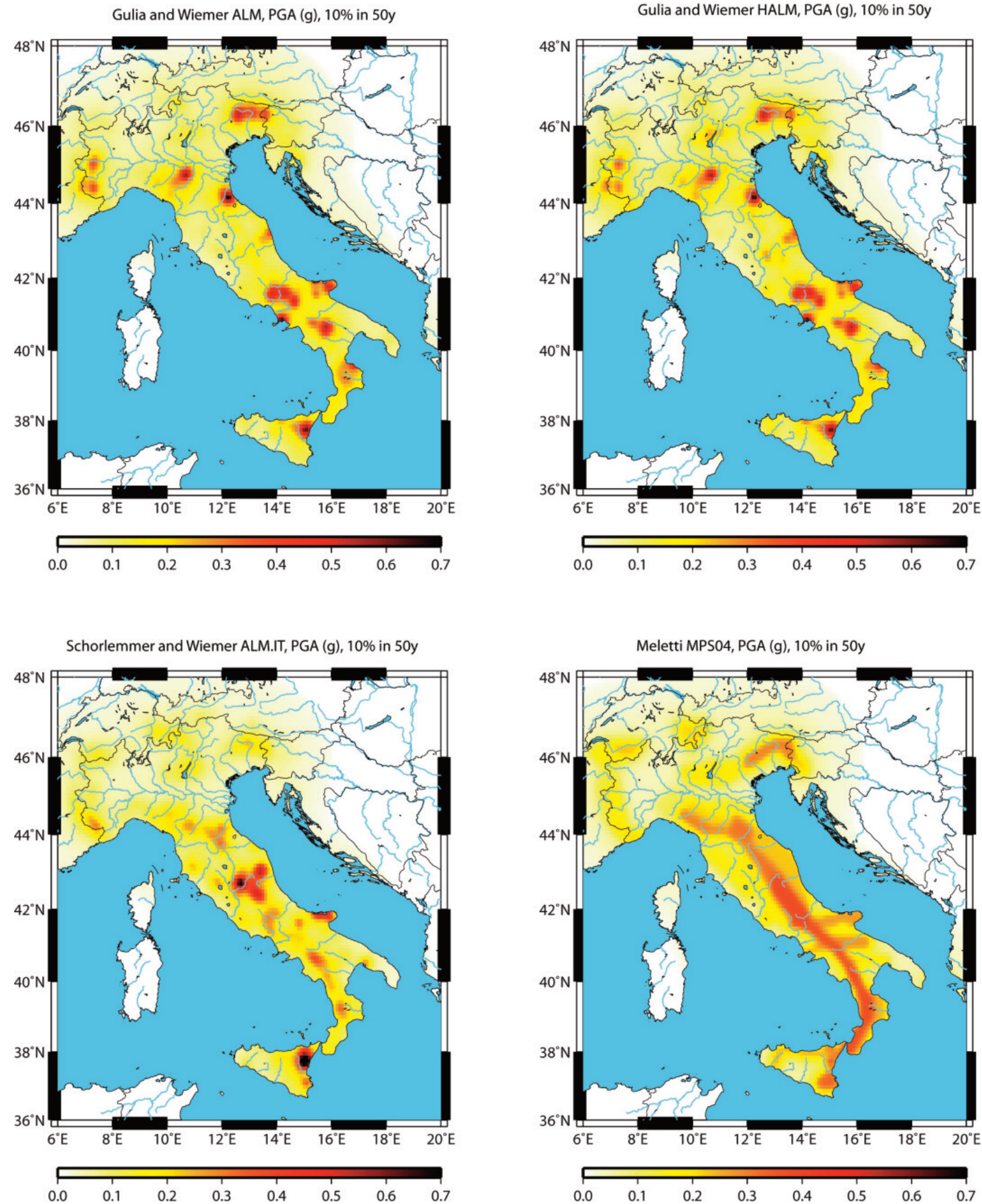

Figure 10. Hazard maps in terms of peak ground acceleration in percent of $g$ for the ALM (top, left), the HALM (top, right) and the ALM.IT (bottom, left), along with a simplified version of the MPS04 (bottom, right) [MPS Working Group 2004]. Forecast rates of each model at each grid node were used, with a single ground-motion prediction equation and computed at the $10 \%$ in 50 year probability levels using OpenSHA.

ALM, the necessary adjustments here were quite minor: we only adjusted the overall $b$-value (Figure 1), and also, of course, we had to determine the dataset upon which we derived the $M_{c}$, and the $b$-value and $a$-value. The overall performance of the ALM (Figures 8 and 9) appears satisfactory; however, we did wonder about the systematic over prediction in all of the magnitude bins (Figure 8) when compared to the past catalogs, as well as the poor results in the L-Test (Figure 9). As we did not want to "tune" our model to the tests applied, we did not perform a systematic optimization with respect to the past data.

The motivation for the proposing of two modified forms of the ALM, as the ALM.IT and the HALM, largely derived from our own scientific curiosity and an attempt to improve the ALM. The ALM.IT tried to overcome one of the shortcomings of the ALM that we had noticed for California [Schorlemmer et al. 2010a]: the forecast rates were possibly too rough. We thus applied a slight smoothing to the rates. In addition, the ALM.IT used a more conservative approach to determine the completeness magnitude, using the PMC 
rather than the EMR approach. Somewhat surprising to us, this difference appears to have a significant impact on the computed forecasts and the resulting hazard (Figure 10). The HALM, on the other hand, built in more expert knowledge of the seismotectonic zonation. "Common wisdom" in probabilistic hazard assessments includes the expert knowledge of the geology, seismotectonics and geodesy, for instance, and it is an important ingredient in the PSHA assessment that cannot be readily replaced by grid-based smooth hazard approaches [e.g., Frankel 1995, Woo 1996]. The HALM tries to pose this question by establishing a testable model that takes some of the expert knowledge into account. This was a first attempt to address the question of the value of (non-reproducible) expert opinion in PSHA. Given that the ALM and HALM forecasts were quite similar, we suspect that we will not be able to answer this question with any certainty based on the Italian testing region; however, and again, we will also try to implement the HALM approach in other regions.

Finally, a striking difference between the ALM calls the forecast rates and also the resulting hazard (Figure 10) when compared to the classical long-term hazard models. This observation is quite similar for other regions, such as California [Wiemer and Schorlemmer 2007]. It suggests that one of the conclusions we may be able to draw from community supported testing experiments is the degree of stationarity and smoothing needed in the construction of a "successful" hazard model. We are now awaiting the results of the prospective testing.

Acknowledgements. We are grateful to Max Werner for providing the scripts to perform the likelihood tests, Thessa Tormann for assistance in implementing the ALM, Fabian Euchner for assistance in plotting Figure 6, Damiano Monelli for computing the hazard maps (Figure 10), the two anonymous reviewers for providing comments that have helped us to improving our manuscript, and last not least, the editors of this special issue for their patience with this late submission. This study was supported by the EC Project NERIES (contract 026130). Most of the Figures were drawn using Generic Mapping Tool (GMT) [Wessel and Smith 1995] and ZMAP [Wiemer 2001].

\section{References}

Aki, M. (1965). Maximum likelihood estimate of $b$ in the formula $\log N=a-b M$ and its confidence limits, Bull. Earthquakes Res. Inst., Tokyo Univ., 43, 237-239.

Amelung, F. and G. King (1997). Earthquake scaling laws for creeping and non-creeping faults, Geophys. Res. Lett., 24, 507-510.

Amitrano, D. (2003). Brittle-ductile transition and associated seismicity: experimental and numerical studies and relationship with the $b$ value, J. Geophys. Res, 108, 2044.

Bender, B. (1983). Maximum-likelihood estimation of $b$ values for magnitude grouped data, Bull. Seismol. Soc. Am., 73, 831-851.

Castello, B., G. Selvaggi, C. Chiarabba and A. Amato (2006). CSI Catalogo della sismicità italiana 1981-2002, versione
1.1. INGV-CNT, Roma; http:/ / csi.rm.ingv.it/.

Cinti, F.R, L. Faenza, W. Marzocchi, P. Montone (2004). Probability map of the next large earthquakes in Italy, Geochem. Geophys. Geosyst., 5, Q11003; doi: 10.1029/ 2004GC000724.

Field, E. (2007). Overview of the Working Group for the Development of Regional Earthquake Likelihood Models (RELM), Seismol. Res. Lett., 78 (1), 7-16.

Frankel, A. (1995). Mapping seismic hazard in the central and eastern United States, Seismol. Res. Lett., 66, 8-21.

Gardner, J.K. and L. Knopoff (1974). Is the sequence of earthquakes in southern California, with aftershocks removed, poissonian?, Bull. Seismol. Soc. Am., 64 (5), 1363-1367.

Gulia, L. (2010). Detection of quarry and mine blast contamination in European regional catalogues, Nat. Hazards, 53, 229-249; doi: 10.1007/s11069-009-9426-8.

Gulia, L. and S. Wiemer (2010). The influence of tectonic regimes on the earthquake size distribution: A case study for Italy, Geophy. Res. Lett., 37, L10305; doi: 10.1029/2010GL043066.

Helmstetter, A., Y. Kagan and D.D. Jackson (2007). Highresolution Time-independent Grid-based Forecast for $M \geq 5$ Earthquakes in California, Seismol. Res. Lett., 78 (1), 78-86.

Kenneth, P., K.P. Burnhaman and D.R. Anderson (2002). Model selection and multimodel inference: A practical information - Theoric Approach, Springer, New York.

Kostrov, V.V. (1974). Seismic moment and energy of earthquakes and seismic flow of rock, Izv. Acad. Sci. USSR, Phys.Solid Earth, 1, 23-40.

Lolli, B. and P. Gasperini (2006). Comparing different models of aftershock rate decay: The role of catalog incompleteness in the first times after main shock, Tectonophysics, 423, 43-59.

Meletti, C., F. Galadini, G. Valensise, M. Stucchi, R. Basili, S. Barba, G. Vannucci and E. Boschi (2008). A seismic source zone model for the seismic hazard assessment of the Italian territory, Tectonophysics, 450, 85-108; doi: $10.1016 /$ j.tecto.2008.01.003.

Montone, P., M.T. Mariucci, S. Pondrelli and A. Amato (2004). An improved stress map for Italy and surrounding regions (central Mediterranean), J. Geophys. Res., 109, B10410; doi: $10.1029 / 2003$ JB002703.

MPS Working Group (2004). Redazione della mappa di pericolosità sismica prevista dall'Ordinanza PCM 3274 del 20 marzo 2003, Rapporto conclusivo per il Dipartimento della Protezione Civile, INGV, Milano-Roma, April 2004 (MPS04), 65 pp. +5 appendices; http://zonesismiche.mi.ingv.it.

Nanjo, K., D. Schorlemmer, J. Woessner, S. Wiemer and D. Giardini (2010). Earthquake detection capability of the Swiss Network, Geophys. J. Int., 181 (3), 1713-1724; doi: 10.1111/j.1365-246X.2010.04593.x. 
Reasenberg, P. (1985). Second-order moment of central California seismicity: 1969-1982, J. Geophys. Res., 90, 5479-5495.

Scholz, C.H. (1968). The frequency magnitude relation of microfracturing in rock and its relation to earthquakes, Bull. Seismol. Soc. Am., 58 (1), 399-415.

Schorlemmer, D., S. Wiemer and M. Wyss (2004a). Earthquake statistics at Parkfield: 1 . Stationarity of $b$ values, J. Geophys. Res., B12307; doi: 10.1029/2004JB003234.

Schorlemmer, D., S. Wiemer, M. Wyss and D.D. Jackson (2004b). Earthquake statistics at Parkfield: 2. probabilistic forecasting and testing, J. Geophys. Res., B12308; doi: 10.1029/2004JB003235.

Schorlemmer, D. and S. Wiemer (2005). Microseismicity data forecast rupture area, Nature, 434, 1086; doi: 10.1038/ 4341086a.

Schorlemmer, D., S. Wiemer and M. Wyss (2005). Variations in earthquake-size distribution across different stress regimes, Nature, 437, 539-542; doi: 10.1038/nature04094.

Schorlemmer, D., S. Gerstenberger, S. Wiemer, D.D. Jackson and D.A. Rhoades (2007). Earthquake likelihood model testing, Seismol. Res. Lett., 78 (1), 17-29.

Schorlemmer, D. and J. Woessner (2008). Probability of Detecting an Earthquake, Bull. Seismol. Soc. Am., 98 (5), 2103-2117; doi: 10.1785/0120070105.

Schorlemmer, D., J.D. Zechar, M.J. Werner, E.H. Field, D.D. Jackson, T.H. Jordan and the RELM Working Group (2010a). First results of the regional earthquake likelihood models experiment, Pure and Appl. Geophys, 167, 859-876.

Schorlemmer, D., A. Christophersen, A. Rovida, F. Mele, M. Stucchi and W. Marzocchi (2010b). Setting up an earthquake forecast experiment in Italy, Annals of Geophysics, 53, 3 (present issue).

Schorlemmer, D., F. Mele and W. Marzocchi (2010c). A Completeness Analysis of the National Seismic Network of Italy, J. Geophys. Res., 115, B04308; doi: 10.1029/2008JB006097.

Stucchi, M., et alii (2007). DBM04, il database delle osservazioni macrosismiche dei terremoti italiani utilizzate per la compilazione del catalogo parametrico CPTI04, Quaderni di Geofisica, 49, 1-38; http: / / emidius.mi.ingv.it/DBMI04/.

Vannucci, G. and P. Gasperini (2003). A database of revised fault plane solutions for Italy and surrounding regions. Computers \& Geosciences, 29 (7), 903-909.

Vannucci, G. and P. Gasperini (2004). The new release of the database of Earthquake Mechanisms of the Mediterranean Area (EMMA Version 2), Annals of Geophysics, 47 (1), Supplement, 307-334; http: / / ibogfs.df.unibo.it/ user2 / paolo/www/ATLAS/pages/EMMA_READ_ME.html.

Werner, M. and D. Sornette (2008). Magnitude uncertainties impact seismic rate estimates, forecasts and predictability experiments, J. Geophys. Res.; doi: 10.129/2007JB005427.

Wessel, P. and W.H.F. Smith (1995). New version of the generic mapping tools released, Eos. Trans., 76, 329.

Wiemer, S. and M. Wyss (1997). Mapping the frequency- magnitude distribution in asperities: An improved technique to calculate recurrence time?, J. Geophys. Res., 102 (B7), 15115-15128; doi: 10.1029/97JB00726.

Wiemer, S. and K. Katsumata (1999). Spatial variability of seismicity parameters in aftershocks zones, J. Geophys. Res., 104 (B6), 13135-13151.

Wiemer, S. and M. Baer (2000). Mapping and Removing Quarry Blast Events from Seismicity Catalogs, Bull Seismol Soc Am, 90 (2), 525-530.

Wiemer, S. (2001). A Software Package to Analyze Seismicity: ZMAP, Seismol. Res. Lett., 92, 373-382.

Wiemer, S., M. Gerstenberger and E. Hauksson (2002). Properties of the aftershock sequence of the $1999 M_{\mathrm{w}} 7.1$ Hector Mine earthquake: Implications for aftershock hazard, Bull. Seismol. Soc. Am., 92 (4), 1227-1240.

Wiemer, S. and D. Schorlemmer (2007). ALM: An Asperitybased Likelihood Model for California, Seismol. Res. Letters., 78 (1), 134-140.

Woessner, J. and S. Wiemer (2005). Assessing the Quality of Earthquake Catalogues: Estimating the Magnitude of Completeness and its Uncertainty, Bull. Seismol. Soc. Am., 95 (2), 684-698; doi: 10.1785/0120040007.

Woo, G. (1996). Kernel estimation methods for seismic hazard area source modeling, Bull. Seismol. Soc. Am., 86, 353-362.

Wyss, M., D. Schorlemmer and S. Wiemer (2000). Mapping asperities by minima of local recurrence time: The San Jacinto-Elsinore fault zones, J. Geophys. Res., 105, 78297844.

*Corresponding author: Laura Gulia, Istituto Nazionale di Geofisica e Vulcanologia, sezione di Bologna, Italy; email: gulia@bo.ingv.it

(C) 2010 by the Istituto Nazionale di Geofisica e Vulcanologia. All rights reserved. 